\title{
A INCUBADORA TECNOLÓGICA DE COOPERATIVAS POPULARES DA UNIVERSIDADE DO PLANALTO CATARINENSE E A INCUBAČ̃̃ DA COOPERATIVA DE TRABALHO DOS CATADORES DE MATERIAIS RECICLÁVEIS DO MUNICÍPIO DE LAGES, SC
}

\author{
TECHNOLOGY INCUBATOR OF POPULAR COOPERATIVES OF \\ THE PLANALTO CATARINENSE UNIVERSITY AND THE \\ INCUBATION OF WORK COOPERATIVE OF RECYCLABLE \\ MATERIAL COLLECTORS IN THE MUNICIPALITY OF LAGES, SC
}

Sueli Kraus Coelho de Farias* Geraldo Augusto Locks**

\section{RESUMO:}

O objetivo deste texto é refletir sobre a Incubadora Tecnológica de Cooperativas Populares da Universidade do Planalto Catarinense (ITCP UNIPLAC) e o processo de incubação da Cooperativa de Trabalho de Catadores de Materiais Recicláveis do Município de Lages, SC (COOPERLAGES). Descreve-se o contexto de emergência do movimento social da economia solidária, a institucionalização da incubadora, enfatizando sua aproximacão com o universo dos catadores por meio de acões de incubação da cooperativa e o enfrentamento de desafios na gestão interna e na coleta seletiva. Neste processo pedagógico, são destacadas a formação dos catadores, organização, constituição da cooperativa e assinatura do primeiro contrato de prestação de serviço da coleta seletiva de materiais recicláveis entre a cooperativa e a Prefeitura Municipal de Lages, para o período de março de 2015 a março de 2016. A reflexão evidencia o papel da Incubadora no processo de incubação da cooperativa, orientada por princípios e valores da economia solidária, ou seja, autogestão, propriedade coletiva dos meios de produção, cooperação, solidariedade, democracia, responsabilidade com o entorno social, cuidado com o meio ambiente, integrando consumo solidario com sustentabilidade. A pesquisa se caracteriza por uma abordagem qualitativa, bibliográfica, descritiva e explicativa. Trata-se de um estudo de caso, pois reflete sobre uma parte de uma totalidade maior de características similares. Os referenciais teóricos de análise trabalham com a temática da economia solidária, incubadora universitária e política pública de resíduos sólidos. O estudo demonstra que a COOPERLAGES se constitui numa organizacão relevante para seus cooperados, que passam de condicões desumanas para condições mais humanas de vida: que o município de Lages exercita primeiros passos rumo à política nacional de resíduos sólidos, conforme preconiza a Lei 12.305/10; que conforme mostram as ações de incubação, nas gestões interna da cooperativa e da coleta seletiva, residem os maiores obstáculos a serem superados com a participação de todos os atores envolvidos: a prefeitura municipal a comunidade, a cooperativa e a ITCP UNIPLAC, para que se efetive e se consolide a política pública de resíduos sólidos no município de Lages; finalmente, que a universidade tem a oportunidade de fortalecer o ensino, a pesquisa e a extensão socialmente relevante.

Palavras-chave: Catadores de Materiais Recicláveis; Cooperlages; Economia Solidária; Incubadora Tecnológica de Cooperativa Populares.

\section{ABSTRACT:}

The objective of this text is to reflect on the Technological Incubator of Popular Cooperatives of the University of Planalto Catarinense (ITCP UNIPLAC) and the incubation process of the Cooperative of Collectors of Recyclable Materials of the Municipality of Lages, SC, (COOPERLAGES). We describe the emergency context of the social movement of the solidarity economy, the institutionalization of the incubator emphasizing its proximity to the collectors universe through incubation actions of the cooperative and facing the challenges of internal management and selective collection. In this pedagogical process, we highlight the training of collectors, organization, constitution of the cooperative and signature of the first contract of service for the selective collection of recyclable materials between the cooperative and the City Hall of Lages for the period from March 2015 to March 2016. The reflection focuses on the role of the Incubator in the process of incubation of the cooperative guided by principles and values of solidarity economy, namely, self-management, collective ownership of the means of production, cooperation, solidarity, democracy, responsibility with the social environment, environmental awareness and the integration of solidary consumption with sustainability. The research is characterized by a qualitative, bibliographic, descriptive and explanatory approach. This is a case study because it reflects on a part of a greater totality of similar characteristics. The theoretical background addresses the themes of solidarity economy, university incubator and public policy of solid waste. The study shows that COOPERLAGES constitutes an organization that is relevant to its members, as they go from inhuman conditions to more humane conditions of life; That the municipality of Lages exercises first steps towards the national solid waste policy, as provided for in the Law 12,305 / 10; As shown by the incubation actions, in the internal management of the cooperative and the selective collection, the greatest obstacles to be overcome with the participation of all the actors involved are: the municipal government, the community, the cooperative and the UNIPLAC ITCP so that the public policy of solid waste is made effective and is consolidated in the municipality of Lages; Finally, that the university has the opportunity to strengthen teaching, research and socially relevant extension.

Keywords: Recyclable Material Collectors; Cooperlages; Solidarity Economy; Technological Incubator of the Popular Cooperative.

\footnotetext{
* Professora da Universidade do Planalto Catarinense (UNIPLAC), Lages - SC, Brasil. E-mail: sueli_kraus_farias@hotmail.com ${ }^{* *}$ Professora da Universidade do Planalto Catarinense (UNIPLAC), Lages - SC, Brasil. E-mail: geraldolocks@gmail.com

${ }^{* * *}$ Aluno de Doutorado da Universidade do Vale do Rio dos Sinos (UNISINOS), São Leopoldo - RS, Brasil. E-mail: joaoeduuardo1@gmail.com
} 


\section{Introdução}

O intuito deste trabalho é refletir sobre as ações desenvolvidas pela Incubadora Tecnológica de Cooperativas Populares da Universidade do Planalto Catarinense (ITCP UNIPLAC) no processo de incubação da Cooperativa de Trabalho de Catadores de Materiais Recicláveis do Município de Lages, SC (COOPERLAGES). Descreve-se o contexto de emergência do movimento social da economia solidária, a institucionalização da incubadora, enfatizando sua aproximação com o universo dos catadores por meio de ações de incubação da cooperativa e o enfrentamento de desafios na gestão interna e na coleta seletiva.

Nas ações pedagógicas, são destacadas a formação dos catadores, organização, constituição da cooperativa e assinatura do primeiro contrato de prestação de serviço da coleta seletiva de materiais recicláveis entre a cooperativa e a Prefeitura Municipal de Lages para o período de março de 2015 a março de 2016. A reflexão evidencia o processo de incubação da cooperativa, orientada por princípios e valores da economia solidária, ou seja, autogestão, propriedade coletiva dos meios de produção, cooperação, geração de trabalho e renda, distribuição equitativa dos resultados do trabalho associado, solidariedade, responsabilidade com o entorno social, cuidado com o meio ambiente, integrando consumo solidário com sustentabilidade.

A pesquisa tem uma abordagem qualitativa, bibliográfica, documental, descritiva e explicativa. De acordo com Gil (2008), as pesquisas descritivas possuem como objetivo a descrição das características de uma população, fenômeno ou de uma experiência. É também uma pesquisa participativa, na medida em que seus autores integram a equipe da incubadora e atuam junto à cooperativa. Neste sentido, encontram-se profundamente envolvidos com este coletivo pesquisado. Enquanto pesquisa participativa, afirmamos o papel do pesquisador como um animador social e de sua pesquisa como serviço à emancipação humana e à transformação social, como refletem Adams e Moretti (2011).

Muitas informações e reflexões inseridas no texto são testemunhadas pela participação na prática social da incubação como ato educativo para pesquisadores e pesquisandos. Trata-se ainda de um estudo de caso, pois como anuncia Triviños (2013), nesta perspectiva toma-se para investigação uma parte de um universo mais amplo relacionado com o objeto de estudo, pois a ITCP atua com outras cooperativas de catadores na região do Planalto Catarinense, bem como existem em outras partes do país inúmeras incubadoras envolvidas em trabalhos de pré-incubação, incubação e pós-incubação de dezenas de cooperativas de catadores. O estudo foi realizado ainda por meio de observações, tendo por referências as práticas realizadas, agregando-se a utilização de registros como relatórios, diários de campo e atas do banco de dados da incubadora.

Os referenciais teóricos utilizados são de autores que refletem o cooperativismo, a economia solidária, a relevância de uma incubadora universitária, a realidade dos catadores de materiais recicláveis, como Arcanjo e Oliveira (2017) Varanda e Bocayuva (2009), Scariot
(2017), entre outros, e a Lei n. 12.503/2010, que instituiu a Política Nacional de Resíduos Sólidos. Espera-se que, com este trabalho, se possibilite maior visibilidade às ações da ITCP, da constituição e atuação da COOPERLAGES com um ator coletivo na implementação da política pública dos resíduos sólidos no município de Lages. Ainda, se demonstrem os principais desafios e as possibilidades que podem ser encontrados neste empreendimento no qual os princípios e valores da econômica solidária movem e orientam os atores envolvidos. Finalmente, aponta-se para a relevância do trabalho realizado a partir de uma Universidade comunitária.

\section{A ITCP UNIPLAC: contexto e origem da Incubadora}

É importante descrever o contexto mais amplo no qual surge a ITCP. A economia solidária emergiu na região concomitantemente ao movimento social nacional desta "outra economia". A economia brasileira nos anos de 1980 vivia uma crise caracterizada por recessão, alto índice de inflação, desemprego, inclusive fechamento de empresas. Por diferentes regiões do Brasil, apoiados por organizações não governamentais, especialmente a Caritas Brasileira, grupos de trabalhadores e trabalhadoras se reúnem com a finalidade de constituir empreendimentos econômicos solidários geradores de trabalho e renda. Alguns grupos de desempregados assumem empresas com falência declarada e passam a recuperá-las, sob os princípios da autogestão, solidariedade e distribuição equitativa dos excedentes econômicos entre seus membros.

O cenário nacional se replica em Santa Catarina. No meio urbano e rural de Lages e região, surgem grupos de agricultores e operários desempregados, especialmente da construção civil, que passam a se organizar sob a orientação dos valores e princípios da economia solidária. A Cáritas Diocesana de Lages, as Pastorais Sociais, como Comissão Pastoral Operária (CPO), Comissão Pastoral da Terra (CPT), posteriormente o Centro Vianei de Educação Popular, terão importante papel na articulação e assessoria a estes grupos formalizados em associações, cooperativas ou sem formalização alguma. Grande parte destes grupos era constituída por mulheres que buscavam complementação da renda familiar.

Neste movimento social, a ITCP era um sonho que se tornou realidade. Em 2001, durante a realização da primeira feira estadual de economia solidária, realizada em Lages, constituiu-se o fórum regional de economia solidária do Planalto Catarinense. Representantes de entidades apoiadoras e integrantes de empreendimentos solidários que constituíam o fórum, na medida em que encontravam dificuldades no apoio aos empreendimentos, demandavam a ação de uma incubadora na UNIPLAC que fosse capaz de oferecer uma assessoria interdisciplinar, conhecimento, metodologias e tecnologias sociais inovadoras.

Importante ressaltar que a economia solidária somente conquistaria status de política pública em 2003, quando o Governo Lula institui a Secretaria Nacional de Economia Solidária, vinculada ao 
Ministério de Trabalho e Renda. A partir de então, constatou-se um avanço na articulação, organização, formação de empreendimentos e alguns investimentos públicos dirigidos à economia solidária. É neste contexto que as Universidades passam a contar com alguns recursos, com a finalidade de institucionalizar suas incubadoras, atualmente 150 espalhadas pelo país.

Em 2013, durante debate realizado no Curso de Extensão Programa de Ensino Superior para o Desenvolvimento Regional (PROESDE) da UNIPLAC, um estudante questionava "por que a UNIPLAC não tem uma incubadora de economia solidária?". Coincidentemente, naquele período estava aberta a Chamada Pública No $\mathrm{N}^{\circ}$ 089/2013 do Conselho Nacional de Desenvolvimento Científico e Tecnológico (CNPq), em articulação com a SENAES/PRONINC, cujo objetivo era apoiar as incubadoras já existentes ou a institucionalização de novas incubadoras. Um grupo de professores e professoras da UNIPLAC e de agentes de entidades apoiadoras se reúnem e responderam a Chamada, tendo sua aprovação em dezembro daquele ano.

A Universidade não desconhecia a importância de uma incubadora de economia solidária. Um de seus professores a representava no Fórum Regional de Economia Solidária, e seria este representante o protagonizador da iniciativa de responder a Chamada e coordenar posteriormente o Projeto da Incubadora. Importante registrar que, no seu Plano de Desenvolvimento Institucional (PDI, 2010-2018), encontrava-se prevista a "Meta" de apoiar empreendimentos econômicos solidários. Uma feira de agricultores agroecológicos, a partir de 2006, foi implantada no espaço interno da Universidade, existente até hoje, embora não tenha relação direta com o movimento social da economia solidária na região.

O Projeto de Extensão da ITCP nasce no Grupo de Estudos em Desenvolvimento Territorial: políticas e práticas (GEDETER), vinculado ao Programa de PósGraduação Mestrado em Educação (PPGE) da UNIPLAC.

É na linha de pesquisa "Educação e economia solidária" que o Projeto da Incubadora iria desenvolver seu trabalho de disseminação da economia solidária, apoio técnico e assessoramento aos empreendimentos econômicos solidários, por meio do ensino, pesquisa e extensão. Uma metodologia de trabalho é desenvolvida com a finalidade de possibilitar efetividade nas ações e dar visibilidade à ITCP junto à universidade, ao movimento da economia solidária e à sociedade. A equipe passou a se reunir sistematicamente às quintasfeiras, período vespertino, constituindo espaço de reflexão, relatos de ações, reflexões sobre a prática social e encaminhamentos de novas ações em vista da práxis.

Após sua organização inicial, inserção no ambiente da economia solidária, com $\mathrm{o}$ fito de institucionalização, a ITCP foi lançada oficialmente no mês de agosto de 2014, em ato público, com presença da reitoria, de professores, acadêmicos e representantes de organizações da economia solidária de Lages e região.

A ITCP visa desenvolver a metodologia de incubação compreendida enquanto processo de formação, assessoria técnica e política, disseminação de tecnologia apropriada e de gestão voltadas à consolidação e conquista de condições necessárias para a autonomia organizacional e a viabilidade de empreendimentos de economia solidária no território de abrangência e atuação da Universidade. Este território compreende o município de Lages e Região da Serra Catarinense, um conjunto de 18 municípios que compõem a Associação dos Municípios da Região Serrana (AMURES).

Varanda e Bocayuva (2009, p. 82) descrevem a importância da presença e ação das incubadoras nas instituições de ensino superior:

\begin{abstract}
As incubadoras (Universidades públicas ou comunitárias e centros federais de educação e tecnologia) apresentam uma possibilidade concreta de articulação de demandas dos EES por conhecimentos e tecnologias apropriadas e a potencial "oferta" (desenvolvimento ou de disseminação) dessas soluções por parte da instituição de ensino e pesquisa. Além disso, ao fomentar o diálogo duradouro entre as instituições de ensino superior e nas comunidades nas quais estão inseridas as incubadoras, o PRONINC, pode ensejar o desenvolvimento de novas tecnologias apropriadas e metodologias de enfrentamento a pobreza. Por isso, o "processo metodológico de incubação" foi reconhecido como uma tecnologia social e sua replicação tem sido incentivada pelo Proninc e pela Rede de Tecnologia Social (RTS).
\end{abstract}

Foi com o movimento social da economia solidária no país que, no final da década de 1980 , iniciaram-se as primeiras incubadoras universitárias. Como afirmam os autores, elas vêm para responder demandas de conhecimentos e tecnologias apropriadas oriundos dos empreendimentos econômicos solidários.

A ITCP, por sua vez, se insere na universidade como um projeto de extensão. A concepção de extensão na tradição da cultura universitária brasileira é hierarquicamente inferior ao status colocado para o ensino e a pesquisa. No denominado tripé ensinopesquisa e extensão, que se afirma apoiar uma instituição de ensino superior, identifica-se uma deficiência localizada na extensão. As incubadoras universitárias surgiram e agem para alterar esta visão deficiente sobre o lugar da extensão. Afinal, para quê servem o conhecimento, a produção de novos conhecimentos se não proveem emancipação humana e transformação social?

A ITCP, desde sua origem, articula ensino, pesquisa e extensão de forma horizontal. A pesquisa emerge e retorna com seus resultados para os processos de incubação. A UNIPLAC se caracteriza em seus Estatutos Sociais por se identificar com uma universidade comunitária, ou seja, ela é dirigida por um Conselho de representantes da sociedade civil e do Estado local, bem como não tem fins lucrativos. Os recursos percebidos devem ser aplicados no desenvolvimento em sua missão. Ou seja, trata-se de uma "universidade socialmente relevante", como descrevem Mello, Almeida Filho e Ribeiro (2009). A perspectiva de análise desses ex-reitores de universidades gera sérias implicações, haja vista que muda substancialmente o caráter do ensino, pesquisa e extensão. Esta é pensada curricularmente e não mais como uma ação social isolada da universidade. Neste sentido, a ITCP vem se inserindo institucionalmente como um Programa Permanente de Extensão. 
Uma incubadora "populariza a universidade", afirmava o ícone da economia solidária no Brasil, Paul Singer, em encontro de incubadoras universitárias em Brasília, em 2015. Torna-se popular na medida em que a atuação de uma incubadora foca os setores sociais populares ou excluídos da sociedade, fazendo do conhecimento um serviço a estes setores, já que promove processos emancipatórios de cidadãos $\mathrm{e}$ transformadores da realidade.

No caso específico da ITCP, pode-se afirmar que vários fatores contribuem para este movimento: uma equipe multidisciplinar formada por professores, estudantes, técnicos; uma metodologia de pesquisa que assume a epistemologia da pesquisa participativa / pesquisa ação e a educação popular. Aprende-se a relativizar o conhecimento produzido na universidade e o conhecimento popular, na consciência de que ambos são parciais e complementares, mas, associadas, produzem inovações e tecnologias sociais adequadas em vista de novas realidades.

Em síntese, o que faz uma incubadora de economia solidária? Atua para dentro e para fora da universidade. Os primeiros aprendizes são os integrantes de sua equipe de trabalho. Dissemina-se o campo da economia solidária na cultura acadêmica por meio do ensino, pesquisa e extensão. Não qualquer extensão, uma ação que tenciona estruturalmente o modo de conceber e organizar o modo de produção da sociedade, uma vez que a economia solidária tem, no seu embate, a contradição direta com o sistema do capital e propõe um paradigma alternativo de sociedade. Para fora, uma ITCP faz incubação. Aprende e oferece conhecimentos que contribuem para o avanço da economia solidária, por meio dos empreendimentos econômicos solidários e da política pública desta "outra economia". Fortalece o movimento social da economia solidária construído pelo Fórum Regional, Feiras, Conselho Municipal, junto com outras Entidades Apoiadoras.

Na UNIPLAC, a ITCP e o campo da economia solidária estão fazendo os primeiros passos. Quando da visita de avaliação institucional realizada pelo Ministério de Educação neste 2017, a ITCP e suas ações de incubação foram avaliadas como de "grande relevância para o desenvolvimento socioeconômico do Planalto Catarinense". Comprovadamente, um sinal positivo de comprovação de sua trajetória educativa desenvolvida até o tempo histórico presente.

\section{ITCP UNIPLAC e a parceria com o CISAMA}

O Consórcio Intermunicipal Serra Catarinense (CISAMA) é uma organização autárquica a serviço da Associação dos Municípios da Região Serrana (AMURES). Conforme sua homepage, tem como finalidade promover o desenvolvimento humano, social, cultural e econômico do território onde atua, de maneira articulada e em regime de estreita cooperação entre os consorciados e com outras entidades públicas, privadas e da sociedade civil, nacionais e ou estrangeiras, formalizadas através do instrumento Contrato de Programa. O CISAMA desenvolve outros programas, como saneamento básico, meio ambiente, atenção à sanidade, segurança alimentar, infraestrutura urbana e rural, assessoria aos sistemas municipais de educação e gestão integrada de resíduos sólidos.

No final de 2014, o CISAMA procurou a ITCP com o objetivo de realizar o primeiro encontro regional de catadores. É que esta entidade vinha desenvolvendo um Programa Intermunicipal de Gestão Integrada de Resíduos Sólidos (PIGIRS) na área de abrangência da AMURES, tendo por base a Lei 12.305/10. Neste marco legal encontram-se as diretrizes fundamentais que responsabilizam municípios, empresas e a sociedade no cuidado com o meio ambiente, com ênfase na coleta e destinação dos resíduos sólidos.

Quando trata da coleta seletiva, repetidamente traz os catadores enquanto sujeitos coletivos organizados a serem preferencialmente valorizados e contratados pelo poder público, como prestadores de serviço à municipalidade. Portanto, a condição para que um determinado município estabeleça algum contrato com catadores é que eles estejam formalizados em associações ou cooperativas, conforme legislação nacional.

A ITCP e o CISAMA realizaram o primeiro encontro regional de catadores com 47 participantes representando 9 municípios. A partir desta data, agregaram-se as ações da incubadora à assessoria à organização dos catadores no Planalto Catarinense. Em 2015, constituiu-se a Cooperativa de Trabalho de Catadores do Município de São Joaquim (COOPERAC); em dezembro de 2016, a COOPERLAGES e em 2017, a Cooperativa de Trabalho dos Catadores de Otacílio Costa (COOPERCOC). O PIGIRS propõe a constituição de outras cooperativas na região, apontando para uma perspectiva de trabalho nesta parceria, conforme está projetado para, no mínimo, cinco anos.

\section{A constituição da COOPERLAGES}

Em maio de 2016, a ITCP iniciou as ações de incubação da futura COOPERLAGES. As primeiras aproximações deram-se a partir de um diagnóstico individual e do grupo de catadores que ocupava um barracão de propriedade da prefeitura de Lages, localizado no bairro São Miguel. Seis do grupo de 13 catadores tinham origem de trabalho na catação de materiais recicláveis no antigo lixão da cidade. $\mathrm{Na}$ passagem do milênio, mediados por um agente social com experiência no cooperativismo tradicional e de profunda sensibilidade com os cuidados com o meio ambiente, estes catadores organizaram-se na Cooperativa de Reciclagem do Município de Lages (COOPERCICLA), a primeira cooperativa de catadores da cidade, que, sob esta liderança, teve forte repercussão diante da população e do poder público. $\mathrm{O}$ falecimento deste agente impactou o futuro desta organização, que sob o comando hierárquico de uma família, ainda que tivesse o apoio do poder público, inclusive financeiro, em 2012, a cooperativa já não mais existia. Sua principal liderança partidarizou-se, ocupando inclusive um cargo comissionado na atual administração da prefeitura.

Os 13 catadores atuavam de modo espontâneo no trabalho de separação de materiais recicláveis, 
coletados por funcionários da Secretaria Municipal do Meio Ambiente. De forma ilegal e sem a fiscalização dos órgãos competentes, o grupo de catadores ocupava o barracão, e de modo informal conseguia gerar uma renda mensal individual de, aproximadamente, 150 a 200 reais (47 dólares). Ou seja, observa-se que não havia, no município de Lages, uma política pública voltada para a coleta seletiva de materiais recicláveis, segundo preconiza a Lei $12.305 / 2010$. Este fato incomodava alguns funcionários de carreira que atuavam junto à Secretaria do Meio Ambiente. O modelo implantado funcionava de modo insatisfatório diante do Plano de Coleta Seletiva existente e das exigências que vinham sendo apresentadas pela Promotoria do Meio Ambiente.

Foi neste contexto que representantes da Secretaria do Meio Ambiente apresentaram à ITCP a proposta de organizar os catadores que atuavam no barracão São Miguel em uma cooperativa. Aceita a proposição, tratou-se de estabelecer um Termo de Convênio entre a FUNDAÇÃO UNIPLAC e a Prefeitura de Lages para que a incubadora tivesse condições materiais e humanas (professores e estudantes bolsistas) para a realização dos trabalhos.

Em outubro de 2016, iniciou-se o processo formativo desencadeado pela ITCP incubadora junto ao grupo de catadores. Um curso, estruturado em 20 horas, privilegiou temas como "História de vida", "Dinâmica de Grupo", "Economia Solidária", "O sistema econômico capitalista", "Organização dos Catadores" e a "Economia Doméstica". O fechamento deste curso resultou na avaliação de que a situação dos catadores naquele momento exigia mudança em vista de melhores condições de vida. E que a constituição de uma cooperativa seria o caminho para alcançar tal finalidade. Mais, que o modelo de coleta seletiva e as condições de trabalho dos catadores que reciclavam e destinavam os recursos eram extremamentes precários.

Outro estágio relevante deste processo foi a elaboração de um plano de trabalho específico voltado para a constituição da cooperativa. A ITCP, com sua equipe multidisciplinar e o CISAMA, cujo diretor acumulava significativa experiência no campo do cooperativismo no meio rural na região do Planalto Catarinense, aliaram-se na execução desta finalidade. Ambos acordaram que não estava em cena somente a preocupação com a fundação de uma cooperativa dentro do marco legal brasileiro de cooperativas de trabalho, mas buscava-se uma cooperativa orientada pelos princípios e valores da economia solidária, isto é, que se caracterizasse por um empreendimento econômico solidário. Segundo Arcanjo e Oliveira (2017, p. 232), citando a SENAES (2016),

a)Economia Solidária (ES): o conjunto de atividades econômicas [...] - organizadas e realizadas solidariamente por trabalhadores/as sob a forma coletiva e autogestionária. Este conceito geral explicita os valores e princípios fundamentais da $\mathrm{ES}$ : cooperação, autogestão, solidariedade e dimensão econômica.

b)Empreendimentos Econômicos Solidários (EES): são aquelas organizações coletivas $[\ldots]$ tais como: associações, cooperativas, empresas autogestionárias, grupos de produção, clubes de trocas, redes etc.; [...] permanentes, [...] que disponham ou não de registro legal, prevalecendo a existência real e que realizam atividades econômicas de produção de bens, de prestação de serviços, de fundos de crédito [...], de comercialização [...] e de consumo solidário.
c)Entidades de Apoio, Assessoria e Fomento à Economia Solidária (EAF): Foram definidas enquanto aquelas organizações que desenvolvem ações nas várias modalidades de apoio direto junto aos empreendimentos econômicos solidários [...].

Os conceitos acima representam, a rigor, a intencionalidade de constituir a COOPERLAGES naquele momento histórico. A cooperativa deveria se fundar em dois grandes pilares: autogestão, ou seja, uma gestão realizada com a participação de todos os cooperados e que eles fossem os proprietários dos meios de produção; a cooperativa enquanto EES fosse prestadora de serviço de forma legalizada, tendo em foco a realização da coleta seletiva da cidade; finalmente, um empreendimento aberto para receber apoios de entidades apoiadoras que viessem contribuir para a sua consolidação.

Mais uma etapa de formação foi sendo implementada no sentido de buscar a constituição da cooperativa. Ela se organizou em três grandes temas: a) economia solidária: história, princípios, valores, características de um empreendimento econômico solidário; a política pública de economia solidária; a lei municipal de economia solidária; b) A Lei 12.305/10 que instituiu a Política Nacional de Resíduos Sólidos; c) o Estatuto Social da Cooperativa de Trabalho de Materiais Recicláveis do Município de Lages. A escolha dos temas foi absolutamente arbitrária, tendo em vista sua culminância do processo com a assembleia de fundação da cooperativa, incluindo indicação de nomes para compor a Diretoria, definição de cotas e percentual para o Fundo de Reserva e Fundo Rotativo.

$\mathrm{O}$ grupo de catadores demonstrava ansiedade e pressa no desdobramento dessa etapa de formação. Contudo, a equipe da incubadora estava consciente da necessidade de incorporar tal capacitação dos futuros integrantes da cooperativa para que o empreendimento tivesse um desenvolvimento coerente com os princípios da economia solidária e do desempenho satisfatório da cooperativa no cumprimento de suas atribuições.

A metodologia de formação teve por base os princípios da educação popular, isto é, o encontro do conhecimento popular e o conhecimento da academia, tendo consciência de que ambos são parciais e complementares; o diálogo permanente; o ponto de partida é a realidade dos sujeitos e a reflexão crítica desta realidade; uma prática social transformadora; o protagonismo de todos os sujeitos envolvidos no processo formativo;

Em dezembro de 2016, realizou-se a assembleia de constituição da Cooperativa, uma etapa formal, necessitando de, no mínimo, 7 (sete) pessoas, conforme a Lei $\mathrm{n}^{\circ}$ 5.764, de 16 de dezembro de 1971 - Lei das Cooperativas. Dezessete foi o número de sócios fundadores. Nessa assembleia, foi definido o nome da cooperativa, a sede e aprovação do seu Estatuto Social. Houve a eleição dos representantes do Conselho de Administração e Conselho Fiscal. No Estatuto, além dos quesitos convencionais da estruturação da cooperativa, estavam arrolados os princípios e valores da economia solidária, um distintivo importante no conjunto das regras da COOPERLAGES.

A etapa seguinte caracterizou-se pelo 
encaminhamento da documentação para o registro junto ao Cartório e à Junta Comercial do Estado, processo burocrático e lento, executado pela equipe da ITCP, uma vez que os catadores não tinham conhecimento da formalização de sua organização.

\section{O Contrato de Prestação de Serviço: Município de Lages e a COOPERLAGES}

Nos três meses de espera do CNPJ da cooperativa, a incubadora passou a mediar as negociações com representantes da Secretaria do Meio Ambiente, Secretaria de Finanças, Procuradoria Geral do Município (PROGEM), COOPERLAGES e CISAMA, em torno do Contrato de Prestação de Serviço da coleta seletiva da cidade a ser realizada pela cooperativa.

Vários encontros foram realizados para se negociarem compromissos, deveres e atribuições das partes contratantes. Um entrave que implicou em muitos debates contundentes foi o modelo de realização da coleta seletiva. A ITCP e o CISAMA, em acordo com a COOPERLAGES, propunham que a coleta seletiva fosse realizada pelos próprios cooperados e para tal iniciativa a Prefeitura cederia os caminhos com combustível e faria a manutenção.

Isto gerou incredulidade e insegurança, expressas, sobretudo, pelo Secretário de Finanças, que negava peremptoriamente o modelo. Uma de suas alegações era de que a proposta colocaria o poder público em risco, principalmente no que se referia aos custos do conjunto da obra, uma vez que, segundo o mesmo, "sobraria para o município possíveis acidentes na coleta seletiva e outros encargos trabalhistas". Este arrazoado demonstrava incompreensões em relação ao estatuto social da cooperativa, inclusive preconceitos em relação ao profissional da catação de materiais recicláveis. O secretário compreendia os cooperados da COOPERLAGES como se imaginariamente estabelecessem vínculos empregatícios com o poder público, quando o estatuto social assegura a autonomia e responsabilidade compartilhada de seus cooperados em todas as ações e destino da cooperativa.

$\mathrm{O}$ modelo de coleta até então realizado por funcionários da Secretaria do Meio Ambiente dividia os representantes do poder público. Esta Secretaria buscava mudança, pois sabia que a coleta era realizada precariamente, os funcionários encontravam-se em situação de desvio de atividade, contratados para uma finalidade e realizando outra. $\mathrm{O}$ modelo proposto era novo para a realidade de Lages, inclusive para as demais cooperativas de catadores de Santa Catarina, mas existentes em outros municípios do país.

Foi com a mediação do Ministério Público, por meio da Promotoria do Meio Ambiente, que o modelo foi sendo acolhido e assumido pelo poder público. O papel da Promotoria foi fundamental na Interpretação da Lei 12.305/10, na fundamentação do papel do município frente à coleta seletiva e o cuidado ambiental.

A assinatura do termo de convênio para a prestação de serviços de coleta seletiva de resíduos junto à Prefeitura Municipal de Lages ocorreu no dia
29 de março de 2016. Além da cedência de três caminhões, o município repassaria R\$22.000 (US 6.940), mensalmente, à COOPERLAGES. O preço de negociação deste valor não saiu barato. A tendência do poder público na relação com a cooperativa era de tratá-la como uma empresa privada. Enquanto a Prefeitura repassa, mensalmente, R $\$ 600.000$ (US 189.274) para a empresa terceirizada realizar a coleta geral de "lixo" da cidade, alimentando o aterro sanitário e tendo novos dividendos com a destinação de materiais recicláveis, tornava-se difícil reconhecer e empenhar ditos valores à cooperativa de catadores que passariam a realizar um serviço ambientalmente sustentável e de inclusão social e produtiva.

Foram três meses de trabalho, a contar da data de encontro da Secretaria do Meio Ambiente com a ITCP e a assinatura final do Contrato. Duas reuniões com os atores envolvidos e o prefeito municipal (Gestão 2013-2016), que manifestara o maior interesse na iniciativa, devem ser registradas nesta breve descrição histórica. A última ocorreu por ocasião da assinatura. Neste episódio, o prefeito convidou todos os cooperados e entidades apoiadoras a acessar ao gabinete oficial do prefeito, quando convidou a diretora administrativa da COOPERLAGES a ocupar a cadeira do executivo, fato que empoderou o coletivo de catadores agora em outras condições de trabalho. Um momento carregado de significado, pois, de outro ângulo, também pode ser interpretado como uma aproximação do poder público junto ao universo dos catadores, sem ignorar o marketing da administração e teor populista tão tradicional na cultura política brasileira.

\section{A COOPERLAGES e os seus desafios: autogestão e coleta seletiva}

Com a assinatura do Contrato de prestação de serviços, o processo de incubação da COOPERLAGES realizada pela ITCP encontrou maior complexidade. Pode-se construir uma linha imaginária da cooperativa entre o antes e o depois do contrato. É fato que a maioria dos catadores, pela sua falta de instrução formal e experiência de cooperação, apresentaria dificuldades em assumir imediatamente 0 planejamento e gestão de seu empreendimento. Daí a importância da incubação, que implica exatamente planejamento, acompanhamento, formação técnica, contábil, financeira, econômica, sobretudo, a atenção psicossocial, devido ao estado de vulnerabilidade das pessoas que compõem o empreendimento.

Scariot (2017), em pesquisa de campo junto aos catadores organizados em cooperativas na Região Noroeste do Estado do Rio Grande do Sul, apresenta peculiaridades sociais e culturais que mostram a complexidade de se trabalharem as reais e concretas ações junto aos catadores em uma cooperativa orientada pelos princípios da economia solidária. Elementos comuns podem ser identificados no espelho da COOPERLAGES.

O catador é um empobrecido econômico, por ser excluído dos bens materiais, o que significa habitação precária, saúde debilitada, alimentação e trabalho inadequados. Empobrecido político, por ser um 
excluído dos bens políticos, como participar da vida social, representar, protagonizar processos socioeducativos; excluído dos bens simbólicos, a saber, os valores da subjetividade como autoestima, reconhecimento social, vínculos sociais precarizados, acolhimento, carinho, bem querer, amor.

No campo do gênero, a constatação é de que, no Brasil, as mulheres formam $70 \%$ da população de pessoas que trabalham na reciclagem.

Imediatista é outra característica, pois o trabalhador cata pela manhã para comer ao meio dia; então, suas necessidades não esperam respostas a curto, médio ou longo prazo; analfabeto ou semianalfabeto, uma vez que não teve oportunidade de acesso ou se acessou evadiu-se da escola por necessidade de sobrevivência. São estigmatizados pela sociedade de "vagabundos", "marginais", "sujos", "perigosos", "drogados; silenciados e invisibilizados, os catadores falam muito pouco diante do agente externo. Quando os catadores exercitam a palavra, revelam um linguajar próprio, desenvolvido no seu mundo do "não lugar", de "não gente". Por este motivo, as lideranças que sobressaem social e politicamente no grupo de catadores vieram de fora ou emergem despercebida e lentamente.

No universo dos catadores encontra-se uma cultura que os diferencia no cenário da diversidade cultural. Diferentes em atitudes, comportamentos e visão de mundo. Eles podem ter origem em outras profissões, apresentam dificuldades de adaptação às novas tecnologias, outras vezes mostram familiaridade de conhecimento com o que pode ser estranho para o não catador.

A profissão dos Catadores foi reconhecida na Classificação Brasileira de Ocupações (CBO) pela Portaria $\mathrm{n}^{\mathrm{O}} 397$, de 9 de outubro de 2002, do Ministério do Trabalho, sob o Código ${ }^{\circ}$ 5.192-05; identifica-se um agente importante no tratamento do "lixo" produzido pela sociedade, conhecedor do trabalho que realiza. O Estado brasileiro, por meio da Lei $12.305 / 10$, compreende as organizações associativas e cooperativas de catadores como sujeitos coletivos indispensáveis na operacionalização e execução da política pública de resíduos sólidos. No judiciário, importantes setores são aliados dos catadores, como temos caracterizado ao longo deste estudo.

No campo empírico de nossa pesquisa, focado na COOPERLAGES, observam-se também percepções e olhares positivos no sentido da valorização dos catadores e de seu trabalho enquanto possibilidade de geração de trabalho e renda e de realização de uma política pública na direção do almejado desenvolvimento sustentável, condição para a vida do planeta Terra.

A ITCP, ao iniciar os processos de incubação com catadores, não conhecia em maiores detalhes o caminho a ser trilhado. Por isto, soprava na memória de alguns de seus educadores sociais um dos jargões da educação popular latino-americana: "el camino se hace al caminar". Os problemas iniciaram-se no dia seguinte ao contrato, durante a realização da coleta seletiva, uma vez que o mesmo preconizava sua realização nos 74 bairros da cidade. Os caminhões cedidos pela Prefeitura já não foram em número de três, como estava previsto. E os dois cedidos para a coleta, por serem veículos vulneráveis pelo seu tempo de uso, começaram a dar problemas técnicos e demandarem longo tempo de oficina. Na lógica do catador, isto não era admissível, um sentimento que gerou, imediatamente, desânimo.

O segundo problema, de maior gravidade, residia nas pessoas envolvidas no trabalho: a situação de vulnerabilidade social do catador. Foi quando a ITCP percebeu que a presença de seus educadores na cooperativa deveria ser diária. Um processo de acompanhamento psicossocial, iniciando com a inscrição de cada cooperado no Cadastro Único (CadÚnico) junto à Secretaria Municipal de Assistência Social, fez-se necessário. Um novo diagnóstico seria implementado para obter informações de cada cooperado, dado que se percebeu um movimento de rotatividade no quadro dos cooperados, alguns deixando a cooperativas e novos ingressando. Num determinado momento, a fila de espera ficou maior que os efetivos da cooperativa, mas matematicamente naquele momento não era possível novas admissões, pois os cálculos de custo e benefício não permitiam, embora para a direção do empreendimento "sempre tem lugar para mais um sócio".

O diagnóstico socioeconômico se impôs para identificar quais programas sociais e políticas públicas participavam os catadores ou teriam direito a participar. A renda inicial obtida pela triagem dos resíduos que chegava à cooperativa era insuficiente para atender as necessidades básicas. Ora, como se referia Marx e Engels em sua Ideologia Alemã, a primeira condição de um ser humano é manter-se vivo para, daí, por meio de seu trabalho, atender suas necessidades básicas (MARX, ENGELS, 1986). Ou seja, nenhum ser humano reproduz sua existência pelo trabalho sem ter as condições humanas para o trabalho, que o humaniza e transforma a natureza e a sociedade.

Diante deste desafio, solicitou-se a suplementação de cestas básicas para um período de três meses, sabendo que o processo educativo instalado pela ITCP não poderia cair na armadilha do assistencialismo ou da tutela do Estado. Contudo, para aquela conjuntura era necessário articular a assistência social para que avançasse o processo de inclusão social e econômico protagonizado pela COOPERLAGES.

A ITCP colocou em campo professores e estudantes dos cursos de Psicologia, Serviço Social e Administração. A tensão no processo de incubação residia na contradição da assistência social aos cooperados rumo à emancipação social por meio do cumprimento das atribuições preconizadas no contrato com a Prefeitura Municipal. "Problematizar" e "refletir" com os cooperados a realidade diária tornouse uma prática social diária, tendo em vista a resolução dos problemas de gestão interna e da coleta seletiva.

Em um empreendimento econômico solidário, os seus integrantes teriam papel decisivo na busca das soluções. Estas não poderiam vir de cima, nem de uma hierarquia interna rígida, como ocorre na lógica do sistema do capital. Os cooperados deveriam opinar e sugerir alternativas ou soluções para superar as situações vivenciadas no dia a dia do empreendimento. Com a suplementação da alimentação dos cooperados, 
o ambiente interno da cooperativa apresentou melhoras significativas. A primeira contribuição dos catadores foi na elaboração do roteiro da coleta seletiva. A Secretaria de Meio Ambiente havia elaborado um plano de coleta seletiva, mas não funcionava. Com a participação dos motoristas e coletores que atuam atrás do caminhão, as melhorarias começaram a aparecer, mudando substancialmente o roteiro. Detalhes como o tamanho do caminhão não permite acesso a determinadas ruas e não eram considerados pelos técnicos da Secretaria, mas foram observadas pelos motoristas catadores.

Outro aspecto relevante a ser considerado no movimento da complexidade pós-contrato foram as exigências da Secretaria de Finanças. Mensalmente, tornou-se indispensável a apresentação de relatório das atividades de produção, renda dos catadores e a prestação de contas para acompanhamento e monitoramento do sistema de coleta seletiva por parte da Prefeitura. Coube à ITCP esta atribuição condicionante do empenho financeiro à cooperativa do mês seguinte, uma oportunidade ímpar para refletir sobre o papel da ITCP no processo de incubação.

\section{A coleta seletiva: um desafio permanente}

A coleta seletiva de materiais recicláveis, no caso da cidade de Lages, coloca vários atores em cena. Primeiro, o poder público responsável pela limpeza urbana, a remoção dos resíduos, está legalmente a cargo das prefeituras municipais. Segundo, uma empresa privada contratada pelo município para realizar a coleta, que geralmente mantém o monopólio deste serviço numa determinada região, como é o caso do campo empírico desta pesquisa. A empresa recebe por tonelada recolhida de resíduos. Terceiro, a sociedade constituída pelos cidadãos, instituições públicas e empresas. Quarto, a presença e atuação da cooperativa de catadores.

Scariot (2017), em sua pesquisa, constatou questões semelhantes àquelas que identificamos entre os atores envolvidos no campo da política pública dos resíduos sólidos. No que tange ao Município, ainda há a necessidade de se adequar à Lei 12.305/10, o que parece não estar bem entendido pelos gestores. Para alguns, a contratação da empresa terceirizada gera uma sensação de que tudo está resolvido, não obstante os problemas de não separação dos resíduos, a manutenção dos aterros sanitários, problemas ambientais e sociais, sem considerar os altos custos deste serviço. Gestores ainda continuam tratando a questão como se estivessem fazendo favor para os catadores, quando discutem sua contratação para a realização da coleta seletiva.

É evidente que a contratação de uma empresa especializada em coleta de resíduos acumula conhecimentos, uma organização prévia oferece maior segurança ao gestor público. Contratar uma cooperativa de catadores implica maiores riscos, sendo necessário investir em formação técnica, oferecer condições sociais e econômicas, sobretudo, confiar neste sujeito coletivo excluído social e da produção e do acesso aos bens necessários à vida. Mas é necessário demonstrar que os custos em novos empenhos da parte da Prefeitura jamais se equiparão àqueles que asseguram o contrato de uma empresa terceirizada.

A empresa terceirizada tem compromisso com a coleta geral. Seu interesse não está na separação e no cuidado ambiental, mas no maior volume de toneladas arrecadados para seus fins de lucro. Ela vende um serviço ao poder público, desresponsabilizando-o de sua atribuição, e isto é de interesse de ambos.

O maior problema reside no terceiro ator, que pode ser chamado de de comunidade. Constata-se um baixo índice de separação e classificação de resíduos nas residências, estabelecimentos comerciais, órgãos públicos. Como afirma Scariot (2017, p. 171), "seja pela fata de hábito, pelo fato de o município não ter coleta seletiva, ou pela desculpa de que a gente separa e depois o caminhão mistura tudo". Quem observa o material que chega na COOPERLAGES percebe que grande percentual é de rejeitos. Isso dificulta o trabalho dos catadores, tanto pela perda de tempo e renda, como pelas condições insalubres, inclusive perigos de cortes nas mãos. Além dos rejeitos ocasionarem mau cheiro e atrairem insetos e roedores, não gera bem-estar para quem permanece, no mínimo, oito horas de trabalho, de segunda a sexta-feira. A COOPERLAGES somente recomenda a separação dos resíduos, mas não solicita que se lavem determinados materiais.

Finalmente, o último ator é a cooperativa de reciclagem. Os catadores têm um conhecimento específico, pode-se dizer especializado na catação e triagem dos resíduos; a geração de trabalho e renda resulta na inclusão social e produtiva. $\mathrm{O}$ espaço físico da cooperativa torna-se uma escola de educação ambiental, uma vez que a cooperativa recebe, semanalmente, instituições escolares de todos os níveis e modalidades de educação.

A cooperativa tem um desafio pela frente. Acertar na coleta seletiva de resíduos a ser realizada nos bairros da cidade. O processo de incubação já demonstrou que este acerto está relacionado a uma responsabilidade compartilhada entre todos os atores envolvidos. Seu ponto de partida está no cumprimento das atribuições preconizadas no Contrato entre a Prefeitura e a cooperativa; disponibilidade e manutenção dos caminhões adequados para acesso em todos os bairros; elaboração de um Plano de Coleta exequível no tempo e na cobertura de ruas e bairros. $\mathrm{O}$ estudo técnico e a experiência dos catadores aliados são fundamentais para se encontrar a estratégia mais eficaz; a responsabilidade da gestão da coleta por parte da cooperativa quanto aos cuidados com os veículos e cumprimento do Plano de Coleta, e um programa de educação ambiental permanente da comunidade, para que faça bem a sua parte no que diz respeito à separação dos resíduos.

A recente história de incubação da COOPERLAGES pela ITCP demonstra que o caminho a ser trilhado é longo, mas seus primeiros passos foram dados. Seguir em frente é preciso e no final deste primeiro ano de Convênio a cooperativa já operava com 30 cooperados. 


\section{Considerações finais}

O objetivo deste texto foi contextualizar a gênese e o desenvolvimento da Incubadora Tecnológica de Cooperativas Populares da Universidade do Planalto Catarinense. $\mathrm{Na}$ esteira desta reflexão, veio para cena o processo de incubação da Cooperativa de Trabalho dos Catadores de Materiais Recicláveis do Município de Lages, SC.

A partir da inserção da pesquisadora na ITCP, tendo por base a observação participativa, descreve-se o contexto de emergência da economia solidária e constituição da incubadora, sua aproximação com o universo dos catadores, as ações de incubação, aspectos históricos e desafios enfrentados pela cooperativa. Destacam-se os primeiros passos de formação dos catadores, organização, constituição da cooperativa e assinatura do convênio de prestação de serviço da coleta seletiva de materiais recicláveis com a Prefeitura Municipal de Lages, no período de março de 2015 a março de 2016. A reflexão evidencia o papel da Incubadora no processo de incubação da cooperativa, orientada por princípios e valores da economia solidária, ou seja, autogestão, propriedade coletiva dos meios de produção, cooperação, solidariedade, democracia, responsabilidade com o entorno social, cuidado com o meio ambiente, integrando consumo solidário com sustentabilidade.

Destacam-se diferentes ações que constituíram o processo de incubação junto à COOPERLAGES, com ênfase para o período decorrente do primeiro Contrato de Prestação de Serviço da coleta seletiva de resíduos sólidos. As ações vão desde o acompanhamento psicossocial de cooperados, implantação de infraestrutura no ambiente de trabalho, a gestão interna da cooperativa e a gestão da coleta seletiva. O maior desafio enfrentado e que permanece é o da plena realização da coleta. Adiantou-se que o êxito desta atividade situa-se na tensão dos atores envolvidos: poder público, comunidade e a cooperativa.

A COOPERLAGES, com um ano de formalização e com todos os desafios, vem se constituindo em referência no universo das cooperativas de catadores de Santa Catarina. Foi convidada para difundir sua experiência como "case de sucesso" em evento promovido pelo Núcleo de Estudos para Desenvolvimento Sustentável e Inovação Social (DESIS) da Universidade Federal de Santa Catarina, em abril de 2017. Este fato não deve esconder os desafios a serem enfrentados no cotidiano de todos os atores coletivos comprometidos e engajados neste projeto, que se tornou política pública de Estado a partir de 2010. E a UNIPLAC, por sua natureza institucional e missão regional, tem 0 compromisso de acolher e contribuir com iniciativas de ensino, pesquisa e extensão que alavanquem o desenvolvimento socioeconômico regional com sustentabilidade.

\section{Referências}

ADAMS, Telmo; MORETTI, Cheron Zanini. Pesquisa Participativa e Educação Popular: epistemologias do sul. Educação \& Realidade, v. 36, n. 2, p. 327-632, maio/ago. 2011.

MELO, Alex; ALMEIDA-FILHO, Naomar; RIBEIRO, Renato Janine. Por uma Universidade Socialmente Relevante. Portal do MEC, 2009.

ARCANJO, M. A. S.; OLIVEIRA, A. L. M. A criação da Secretaria Nacional de Economia Solidária: Avanços e Retrocessos. Perseu: História, Memória e Política, v. 13, p. 231, 2017.

VARANDA, Ana Paula de Moura; BOCAYUVA, Cunca (Orgs.). Tecnologia Social, Economia Solidaria e políticas Públicas. FASE, IPPUR, LASTRO, Brasil, 2009.

BRASIL. Lei $\mathrm{n}^{\circ} 12.305$ de 2 de agosto de 2010. Institui a Política Nacional de Resíduos Sólidos. Presidência da República Casa Civil. Subchefia para Assuntos Jurídicos. Disponível em:

$<$ http://www.planalto.gov.br/ccivil 03/ ato2007-

2010/2010/1ei/112305.htm>. Acesso em: 14 ago. 2018.

CISAMA. Consórcio Intermunicipal - Serra Catarinense. Disponível em: http://www.cisama.sc.gov.br/. Acesso em: 14 ago. 2018.

GIL, Antonio Carlos. Como elaborar projetos de pesquisa. 5. ed. São Paulo: Atlas, 2008.

MARX, K.; ENGELS, F. A ideologia alemã. São Paulo: Hucitec. 1986.

SCARIOT, Nádia. A socialização Profissional de Catadores de materiais Recicláveis e a Constituição de Saberes Profissionais e Emancipatórios. Dissertação (Mestrado em Educação nas Ciências) - UNIJUI, Ijuí, 2017.

TRIVINOS, Augusto Nibaldo Silva. Introdução à pesquisa em ciências sociais: a pesquisa qualitativa em educação. São Paulo, Atlas, 2013.

UNIPLAC. Plano de Desenvolvimento Institucional. PDI. 2010-2018. Disponível em: www.uniplaclages.edu.br. Acesso em: 14 ago. 2018. 